\title{
Prevalence and Preventive Measures of Prostate Cancer: A Randomized Study in Public and Private Health Care Sector
}

\section{Somia Gul*, Umm-e-Aimon and Maria Ayub}

Faculty of Pharmacy, Jinnah University for Women, Karachi, Pakistan

\begin{abstract}
Prostate cancer accounts for abnormal or uncontrolled division of cells of prostate in male. It is a slow growing cancer which is usually localized rarely metastasized. The growth rate is varies from slow-moderate to high. It mostly occurs in old age and depends on many other factors like weight, height, diet, habit, environment, genetics, and sexual disease. In a prostate cancer, disease stage cannot find unless the patient has symptoms or signs that the cancer has spread. A high PSA level (normal range $4.0 \mathrm{ng}$ per milliliter or less), or a high Gleason score. Gleason scores have often been categorized into groups that show similar biologic behavior: low-grade (well-differentiated), intermediate-grade, moderate to poorly-differentiated or high-grade. This study aims to evaluate occurrence, causes, problem associated with disease and treatment of this cancer in view of the fact to evaluate consequences responsible to contribute carcinoma of prostate. For this purpose study has been conducted at public and private health care sector $(n=100$ patients of prostate cancer). The Gleason score are used to diagnose prostate cancer, $10 \%$ of patients have score $5(4+1), 40 \%$ of patients have score $7(4+3)$ or $(3+4), 44 \%$ of patients have score $9(5+4), 6 \%$ of patients have score $11(5+6)$ which shows that mostly prognostic grade II, III IV, V occur. Mostly traditional prostectomy is used as a treatment and $78 \%$ of the patients got benefit from it. This study concluded that the prostate cancer is occurs due to age factor (old age), fatty diet, tobacco or alcohol intake, duration of cancer is more than 1 year, past history may also be cause like hepatitis, T.B. mostly. Finding of cancer at score 5, 7, 9, 11 and associated complications are hypertension, urinary tract infection, kidney stones.
\end{abstract}

Keywords: Prostate carcinoma; Occurrence; Risk factor; Gleason scores; Treatment

\section{Introduction}

Prostate cancer is the type of carcinoma $[1,2]$ in which the cells of prostate show abnormal and uncontrolled division. Prostrate is a gland present in the male reproductive system, which is present below the bladder of man and it produce fluid for semen [1-3]. Prostate is about the size of a walnut. In cancer, it grows too large and squeezes the urethra. This may slow or stop the normal flow of urine [4-6]. It can be cure if localized, the growth rate is varies from slow-moderaterapid growing but some people can survive after the metastasized of cancer [2,3]. Commonly, its slowly growing, sometimes it show no signs for many years [4]. prostate cancer usually begins at age 37 but predominant mostly in old patients $[1,2]$, rarely in younger than 40 [1-4].The risk for prostate cancer increases with age, with a family history of the disease, genetics, dietary fat and / or meat may increase risk is quite consistent, a high level of sexual activity and / or a history of sexually transmitted disease, with vasectomy. Following tests and examinations are required for diagnosis the prostate cancer; physical examination (by habits, sign and symptoms), digital rectal examination (examination of rectum by which observe the prostate lumps or abnormal area), prostate-specific antigen test, Biopsy (biopsy is used to detect the presence of cancer cells in the prostate and to evaluate how aggressive cancer is likely to be) [7-9].

The process used to find out if cancer has spread within the prostate or to other parts of the body is called staging. The information gathered from the staging process determines the stage of the disease. It is important to know the stage in order to plan treatment. The results of the tests used to diagnose prostate cancer are often also used to stage the disease. In prostate cancer, staging tests may not be done unless the patient has symptoms or signs that the cancer has spread, such as bone pain, a high PSA level (normal range $4.0 \mathrm{ng}$ per milliliter or less) [10], or a high Gleason score [9]. Gleason scores range from 2 to 10 , with 2 representing the well-differentiated tumors and 10 the least-differentiated tumors. Gleason scores have often been categorized into groups that show similar biologic behavior: low-grade (welldifferentiated), intermediate-grade, moderate to poorly-differentiated or high-grade [11]. More recently, an investigation of the Johns Hopkins Radical Prostatectomy Database (1982-2011) led to the proposed reporting of Gleason grades and prognostic grade groups as: Gleason score $\leq 6$ (prognostic grade group I); Gleason score $3+4$ $=7$ (prognostic grade group II); Gleason score $4+3=7$ (prognostic grade group III); Gleason score $4+4=8$ (prognostic grade group IV); Gleason scores 9-10 (prognostic grade group V). Prostate cancers with a Gleason score $\leq 6$ usually have rather good prognoses [12].

The three commonly used treatments for prostate cancer are: radiation therapy, surgery, or combination of radiation and surgery [13]. Initially, several patients responded to the androgen-ablation treatment but over time developed fatal androgen-independent disease [14] which led to the introduction of hormone treatment and chemotherapy. The hormone treatment was either to block the production of adrenal androgen or prevent androgen interaction within the target tissue. Chemotherapy treatment was mainly used for hormone refractory prostate cancer; agents like some agents of chemotherapy (mitoxantrone and corticosteroid, estramustine, vincristine, etoposide, doxorubicin, and the taxanes paclitaxel and docetaxel) are usually involved [15-18]. In the twentieth century,

*Corresponding author: Somia Gul, Faculty of Pharmacy, Jinnah University for Women, Block 5, Karachi, Pakistan, Tel: 922136620857; E-mail: drsomi1983@yahoo.com

Received January 27, 2016; Accepted February 16, 2016; Published February 19, 2016

Citation: Gul S, Umm-e-Aimon, Ayub M (2016) Prevalence and Preventive Measures of Prostate Cancer: A Randomized Study in Public and Private Health Care Sector. Pharm Anal Acta 7: 468. doi:10.4172/2153-2435.1000468

Copyright: (c) $2016 \mathrm{Gul} \mathrm{S,} \mathrm{et} \mathrm{al.} \mathrm{This} \mathrm{is} \mathrm{an} \mathrm{open-access} \mathrm{article} \mathrm{distributed} \mathrm{under}$ the terms of the Creative Commons Attribution License, which permits unrestricted use, distribution, and reproduction in any medium, provided the original author and source are credited. 
prostatectomy and radiation therapy emerged. Prostatectomy involves the use of surgical and radiological techniques to treat prostate cancer [19]. The development and growth of prostate cancer depends on the androgen receptor and its high-affinity binding of dihydrotestosterone, which derives from testosterone. Most prostate tumors regress after therapy to prevent testosterone production by the testes, but the tumors eventually recur and cause death. Now-a-days combination therapy of radiation and prostectomy is used and after that hormonal therapy will done $[20,21]$.

The objective of the study is to find the consequences, causes, risk factors responsible against this life threatening tumor in male called prostate carcinoma in view of the fact to evaluate possible finding that may contribute to trigger prostate carcinoma.

\section{Methodology}

This randomized study conducted from July 2014 to Oct 2014 among different hospitals in public and private health care sectors with the help of clearly defined questionnaire. About 100 patients $(n=100)$ suffering from prostate cancer were selected and evaluated carefully. People from different social, demographical, economic, races included in this study and investigate prostate cancer occurrence, risk factor, grades, family history of patient, past history of patient, complications caused by this cancer, and treatments. All resulting data interpreted and evaluated statistically carefully (Figure 1).

\section{Result and Statistical analysis}

It was statically evaluated that these patients are age of between 69 to 90 years old, weight of patients is in between 70 to $110 \mathrm{~kg}$ and height of patients is 5.5 to 6.4.The fatty diet (lamb, cheese, red meat, etc.) intake by the patients is $32 \%, 48 \%$ of the patient's takes sometime and $20 \%$ of the patients does not take fatty diet. $45 \%$ of patients have smoking habit, $30 \%$ of patient take tobacco, $9 \%$ of alcohol and $14 \%$ patients have don't any bad habit. The duration of cancer of patients is $12 \%$ having less than 6 months, $18 \%$ of patients have more than 6 months. And $60 \%$ of the patients have cancer duration of more than 1 year (Figure 2).

\section{Discussion}

The purpose of current study and research is to recognize the occurrence of prostate cancer. The research is done by the help of survey in which different parameters has been discussed regarding the patient's personal profile, diet, habit, family history, past history, prostate cancer score, duration of cancer, complications due to this cancer, and its treatment (Table 1).

It has been found that prostate cancer is the man's disease it only occurs in man, it is due to the hypertrophy of prostate gland which is present below the bladder and produce fluid for semen. The main risk factors of prostate cancer are age, weight and height.

Age of patients is in between 69 to 90 years old, it begins in young age but predominant in old ages that's why patients have old age. The weight of patients is in between 70 to $110 \mathrm{~kg}$ and height of patient's is 5.5 to 6.4.this shows that the patients are tall and obese with old age (Figure 3).

The fatty diet (lamb, cheese, red meat, etc.) intake by the patients is $32 \%, 48 \%$ of the patient's takes some-time and $20 \%$ of the patients does not take fatty diet . prostate cancer is also occur due to bad habits $45 \%$ of patients have smoking habit, $30 \%$ of patient take tobacco , $9 \%$ of alcohol and $14 \%$ patients have don't any bad habit. The duration of cancer of patients is $12 \%$ having less than 6 months, $18 \%$ of patients have more than 6 months. And $60 \%$ of the patients have cancer duration of more than 1 year. Family history can also be considered as the cause of prostate cancer $42 \%$ of patients have history of cardiac disease, $32 \%$ of patients have history of diabetes mellitus, $16 \%$ of the patients have history of strokes, $10 \%$ of the patients have family history of cancer . it has been observed that prostate cancer can also be occur due to patients disease past history as $12 \%$ of patients had fatty liver, $14 \%$ of patients had T.B, $18 \%$ of patients had hepatitis $B, 10 \%$ of patients had hepatitis $\mathrm{C}$ and $46 \%$ of patients had co-morbid hepatitis $\mathrm{b}$ and T.B. The patients of prostate cancer are suffering from many complications by this research it has been shown that $7 \%$ of patients have hernia, $5 \%$ of patients have asthma, $17 \%$ of patients have hypertension, $16 \%$ of patients have chest infection, $28 \%$ have urinary tract infection and fever, $12 \%$ of patients have gall stone and $23 \%$ of patients have kidney stone. the Gleason score are used to diagnose prostate cancer, $10 \%$ of patients have score 5 $(4+1), 40 \%$ of patients have score $7(4+3)$ or $(3+4), 44 \%$ of patients have score $9(5+4), 6 \%$ of patients have score $11(5+6)$ which shows that mostly prognostic grade II, III, IV, V occur . Different therapies are used to treat prostate cancer single therapy or combination therapy both is used (Table 2). 13\% of patients are treated by Radiation therapy,

\begin{tabular}{|c|c|}
\hline 3.GLEASON SCORE & PERCENTAGE \\
\hline${ }^{*}$ SCORE $5(4+1)$ & $\mathbf{1 0 \%}$ \\
\hline SCORE $7(4+3),(3+4)$ & $\mathbf{4 0 \%}$ \\
\hline SCORE $9(5+4)$ & $\mathbf{4 4 \%}$ \\
\hline SCORE11 $(5+6)$ & $\mathbf{6 \%}$ \\
\hline
\end{tabular}

*Gleason score $5(4+1)=$ those where pattern 4 is most prevalent but some amount of pattern 1 is also observed

Prevalence of prostate cancer in male affected more frequently between age of $60-90$ years, weight $70-110 \mathrm{~kg}$ and height of 5.5-6.4 respectively. Table 1 shows Gleason score, 4 is most prevalent but some amount of pattern 1 is also observed.

Table 1: Score of prostate cancer.

\begin{tabular}{|c|c|}
\hline TREATMENT & PERCENTAGE \\
\hline RADIATION THERAPY & $\mathbf{1 3 \%}$ \\
\hline PROSTECTOMY & $\mathbf{1 2 \%}$ \\
\hline AFTER RADIATION THERAPY PLANE OF SURGERY & $\mathbf{1 5 \%}$ \\
\hline PROSTECTOMY + RADIATION THERAPY & $\mathbf{2 0 \%}$ \\
\hline PLANE FOR SURGERY & $\mathbf{1 2 \%}$ \\
\hline WAIT FOR THERAPY & $\mathbf{1 3 \%}$ \\
\hline AFTER ALL THERAPY HORMONAL THERAPY & $\mathbf{1 1 \%}$ \\
\hline LAMA THERAPY* BEFORE ANY TREATMENT & $\mathbf{4 \%}$ \\
\hline
\end{tabular}

*LAMA therapy (long acting muscarinic agents) mostly refer for addiction patients Table 2: Single and combine treatment plan.

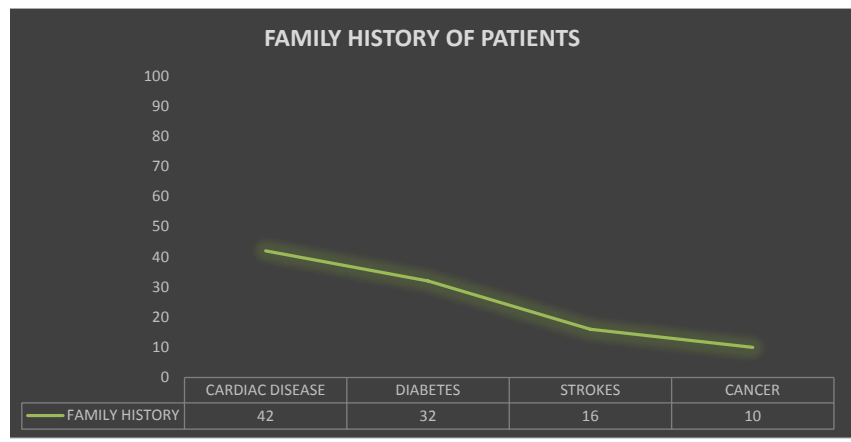

The patients of prostate cancer are suffering from many complications by this research it has been shown that $7 \%$ of patients have hernia, $5 \%$ of patients have asthma, $17 \%$ of patients have hypertension, $16 \%$ of patients have chest infection, $28 \%$ have urinary tract infection and fever, $12 \%$ of patients have gall stone and $23 \%$ of patients have kidney stone (Figure 3 ).

Figure 1: Family history of patient. 
Citation: Gul S, Umm-e-Aimon, Ayub M (2016) Prevalence and Preventive Measures of Prostate Cancer: A Randomized Study in Public and Private Health Care Sector. Pharm Anal Acta 7: 468. doi:10.4172/2153-2435.1000468

$12 \%$ of patients are treated by prostectomy, $20 \%$ of patients are treated by prostectomy + radiation therapy, $12 \%$ of patients have plane for surgery, $13 \%$ of patient are waiting for therapy and $11 \%$ of patients are on hormonal therapy after completion of therapy and $4 \%$ of patients need lama therapy before any therapy this therapy is usually used for addictive patients. By surgery $78 \%$ of patients get benefit and $22 \%$ of patients say "No" they don't get benefit. Maybe this is because of complications which is occurs after surgery or interruption in their lifestyle. Mostly antibiotic like co-Amoxiclave, Ciprofloxacin, etc. Diclofenac sodium, Letrozole, Entecavir, Goserelin (To Treat Prostate Cancer) are prescribed to most of the patients (Figure 4).

\section{Conclusion}

After careful consideration of above retrospective surveillance, we can conclude that the prostate cancer is prevalent most commonly at old age primarily it's a disease dependent of age factor. High fat meal, tobacco, alcohol consumption and other social and life style modification may contribute to triggering factor. Duration of cancer may last for more than a year with past disease condition of

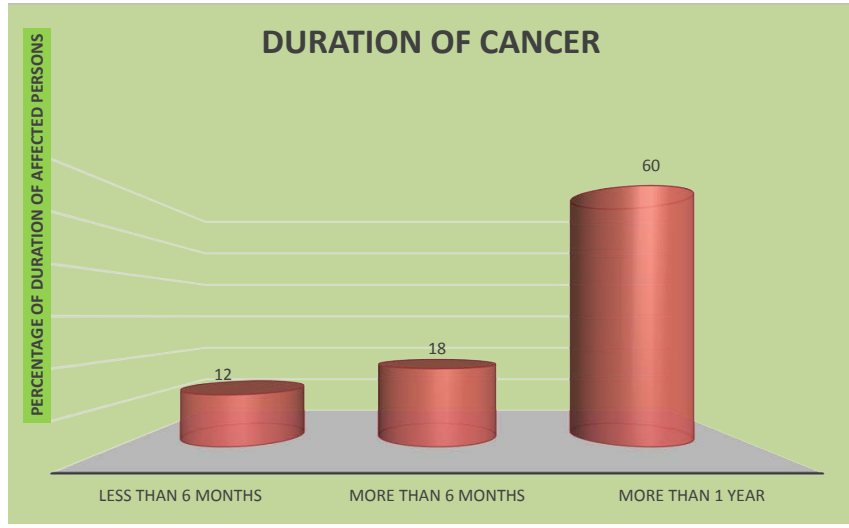

Family history can also be considered as the cause of prostate cancer $42 \%$ of patients have history of cardiac disease, $32 \%$ of patients have history of diabetes mellitus, $16 \%$ of the patients have history of strokes, $10 \%$ of the patients have family history of cancer (Figure 4) it has been observed that prostate cancer can also be occur due to patients disease past history as $12 \%$ of patients had fatty liver, $14 \%$ of patients had T.B, $18 \%$ of patients had hepatitis $B, 10 \%$ of patients had hepatitis $C$ and $46 \%$ of patients had co-morbid hepatitis $B$ and T.B. (Shown in Figures 2 and 4).

Figure 2: Duration of cancer.

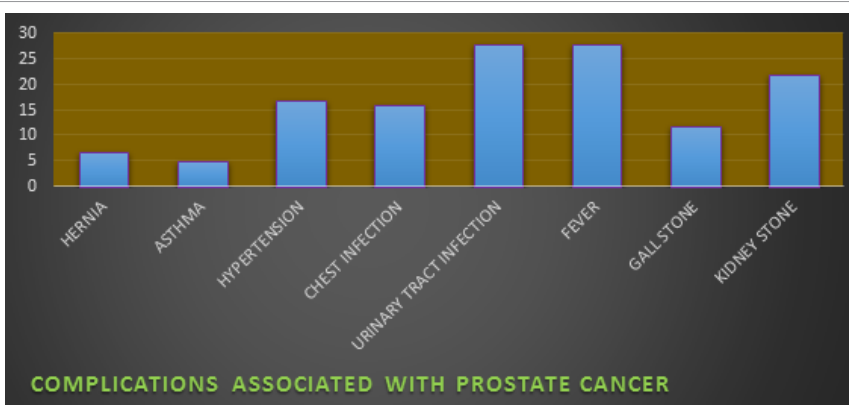

Different therapies are used to treat prostate cancer single therapy or combination therapy both is used. $13 \%$ of patients are treated by Radiation therapy, $12 \%$ of patients are treated by prostectomy, $20 \%$ of patients are treated by prostectomy + radiation therapy, $12 \%$ of patients have plane for surgery, $13 \%$ of patient are waiting for therapy and $11 \%$ of patients are on hormonal therapy after completion of therapy and $4 \%$ of patients need lama therapy before any therapy this therapy is usually used for addictive patients.

Figure 3: Percentage of complication in prostate cancer.

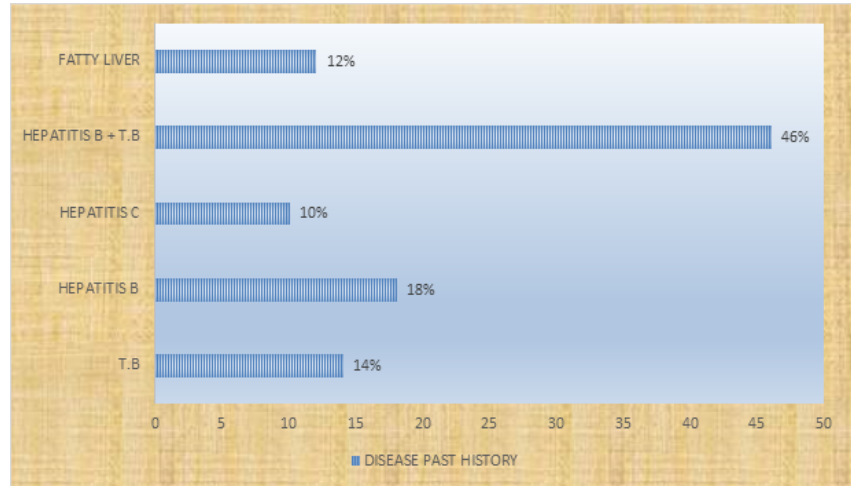

By surgery $78 \%$ of patients get benefit and $22 \%$ of patients say "No" they don't get benefit. Maybe this is because of complications which is occurs after surgery or interruption in their lifestyle. All patients are evaluated in term of life style modification about $45 \%$ had history of smoking, $30 \%$ tobacco, $9 \%$ Alcohol and different behaviors $14 \%$ respectively. About $48 \%$ patients were on high fatty diet, $20 \%$ on low curb diet and $32 \%$ on simple diet plane (Table 2).

Figure 4: Patient past history of disease.

hepatitis. Tuberculosis with liver failure predispose for this cancer. Finding of cancer at score 5, 7, 9, 11 and associated complications are hypertension, urinary tract infection, kidney stones. Gleason score are used to diagnose prostate cancer and here indicating that about $44 \%$ of patients have score $9(5+4), 6 \%$ of patients have score $11(5+6)$ which shows that mostly prognostic grade are II, III, IV, V which treated successfully by radiation therapy mostly.

\section{References}

1. Prostate Cancer-Patient Version, National Cancer Institute: at the National Institute of Health.

2. Prostate Cancer Treatment-for health professionals $\left(\mathrm{PDQ}^{\circledR}\right)$, National Cancer Institute.

3. Prostate cancer, National Library of Medicine, National Institute of Health

4. Prostate cancer Introduction, NHS Choices.

5. SEER Stat Fact Sheets: Prostate Cancer, National Cancer Institute: Surveillance, Epidemiology, and End Results Program.

6. SLU Care Physician; Prostate Cancer, U.S. National Library of Medicine National Institute of Health.

7. (1995) Risk factors for prostate cancer, Imperial Cancer Research Fund, Cancer Epidemiology Unit, Radcliffe Infirmary, Europe PMC 23: 63-77.

8. Peter H Gann (2002) Risk Factors for Prostate Cancer. Rev Urol 4: S3-S10.

9. RY Henry MRCP, DO Mahony MRCPI MD (1999) Treatment of prostate cancer. Journal of clinical pharmacy and therapeutics 24: 93-102.

10. Kumar V, Abbas AK, Fausto N (2005) Robbins and Cotran Pathologic Basis of Disease (9th edn) Elsevier Saunders.

11. Pierorazio PM, Walsh PC, Partin AW, Epstein JI (2013) Prognostic Gleason grade grouping: data based on the modified Gleason scoring system. BJU International 111: 753-760

12. Nana Osei Bonsu (2013) International Journal of Mathematical Sciences in Medicine (2013) 17-31 Statistical Evaluation of Different Prostate Cancer Treatments 1.

13. Feldman BJ, Feldman D (2001) The development of androgen-independent prostate cancer. Nature Reviews Cancer 1: 34-45.

14. Sella A, Kilbourn R, Amato R, Bui C, Zukiwski AA, et al. (1994) Phase II study of ketoconazole combined with weekly doxorubicin in patients with androgenindependent prostate cancer. Journal of Clinical Oncology 12: 683-688.

15. Hudes GR, Nathan F, Khater C, Haas N, Cornfield M, et al. (1997) Phase II trial of 96-hour paclitaxel plus oral estramustine phosphate in metastatic hormonerefractory prostate cancer. Journal of Clinical Oncology 15: 3156-3163. 
Citation: Gul S, Umm-e-Aimon, Ayub M (2016) Prevalence and Preventive Measures of Prostate Cancer: A Randomized Study in Public and Private Health Care Sector. Pharm Anal Acta 7: 468. doi:10.4172/2153-2435.1000468

16. Pienta KJ, Redman B, Hussain M, Cummings G, Esper PS, et al. (1994) Phase II evaluation of oral estramustine and oral etoposide in hormone-refractory adenocarcinoma of the prostate. Journal of Clinical Oncology 12: 2005-2012.

17. Savarese DM, Halabi S, Hars V, Akerley WL, Taplin ME, et al. (2001) Phase Il study of docetaxel, estramustine, and low-dose hydrocortisone in men with hormone-refractory prostate cancer: a final report of CALGB 9780. Cancer and Leukemia Group B. Journal of Clinical Oncology 19: 2509-2516.

18. Young HH (1905) Four cases of radical prostatectomy, Johns Hopkins Bull 16: 315 .
19. Koivisto P, Kononen J, Palmberg C, Tammela T, Hyytinen E, et al. (1997) Androgen Receptor Gene Amplification: A Possible Molecular Mechanism for Androgen Deprivation Therapy Failure in Prostate Cancer, Cancer Res 57 314-319.

20. Linja MJ, Savinainen KJ, Saramäki OR, Tammela TL, Vessella RL, et al. (2001) Amplification and Overexpression of Androgen Receptor Gene in HormoneRefractory Prostate Cancer, Cancer Res 61: 3550-3555.

21. Visakorpi T, Hyytinen E, Koivisto $P$, Tanner M, Keinänen $R$, et al. (1995) In vivo amplification of the androgen receptor gene and progression of human prostate cancer, Nat Genet 9: 401-406. 